\title{
Differential immunostaining of various types of breast carcinomas for growth hormone-releasing hormone receptor - Apocrine epithelium and carcinomas emerging as uniformly positive
}

\author{
BENCE KŐVÁRI, ${ }^{1}$ ORSOLYA RUSZ, ${ }^{2}$ ANDREW V. SCHALLY, ${ }^{3}$ ZSUZSANNA KAHÁN ${ }^{2}$ and \\ GÁBOR CSERNI ${ }^{1,4}$
}

${ }^{1}$ Department of Pathology, University of Szeged, Szeged, Hungary; ${ }^{2}$ Department of Oncotherapy, University of Szeged, Szeged, Hungary; ${ }^{3}$ Veterans Affairs Medical Center, Miami, and Department of Pathology,

Divisions of Hematology/Oncology and Endocrinology, Department of Medicine, University of Miami, Miller School of Medicine, Miami, FL, USA; and ${ }^{4}$ Department of Pathology, Bács-Kiskun County Teaching Hospital, Kecskemét, Hungary

\begin{abstract}
Kővári B, Rusz O, Schally AV, Kahán Z, Cserni G. Differential immunostaining of various types of breast carcinomas for growth hormone-releasing hormone receptor - Apocrine epithelium and carcinomas emerging as uniformly positive. APMIS 2014; 122: 824-831.

Different classes of breast cancers were explored for their positivity for growth hormone-releasing hormone receptors (GHRH-R) in this pilot study, as no systematic evaluation of such tumors has been performed to date. Seventy-two small primary breast carcinomas were evaluated for GHRH-R expression by immunohistochemistry using a polyclonal antibody and a cutoff value of $10 \%$ staining. GHRH-R positivity was detected in $58 \%$ of all cases, $20 / 23(87 \%)$ of invasive lobular carcinomas (ILC) and 22/46 (48\%) of invasive ductal carcinomas (IDC). GHRH-R positivity was more frequent in grade 2 tumors $(86 \%)$, as compared to grade $1(18 \%)$ or grade $3(47 \%)$ cancers. GHRH-R expression was not associated with mitotic scores, the Ki-67 labeling indices or nodal status. IDCs with casting-type calcifications on the mammogram showed positivity for GHRH-R in 9/12 (75\%) cases. Most importantly, apocrine epithelium, and all 10 apocrine carcinomas added later to the study were GHRH-R-positive. These preliminary results suggest a greater than average GHRH-R expression in ILCs and IDCs associated with casting-type calcifications on the mammogram. Apocrine carcinomas seem uniformly positive for GHRH-R. Whether these findings could indicate a potential role of GHRH-antagonists in targeted treatment of these types of breast cancer requires further studies.
\end{abstract}

Key words: Apocrine carcinoma; breast cancer; growth hormone-releasing hormone receptor; immunohistochemistry.

Gábor Cserni, Department of Pathology, University of Szeged, Állomás u. 2., 6720 Szeged, Hungary and Bács-Kiskun County Teaching Hospital, Nyíri út 38., 6000 Kecskemét, Hungary. e-mails: cserni@freemail.hu/csernig@kmk.hu

Growth hormone-releasing hormone (GHRH) has been implicated in carcinogenesis as a growth factor acting both indirectly through the neuroendocrine axis involving the pituitary release of growth hormone $(\mathrm{GH})$ with subsequent expression of insulinlike growth factor 1 (IGF-1) in the liver, and more significantly directly through autocrine and paracrine mechanisms. Many cancers of extrapituitary tissues, including breast carcinomas express GHRH and its receptors (1-3). The presence of both the full length pituitary GHRH receptor (pGHRH-R)

Received 27 August 2013. Accepted 4 November 2013 and its splice variants, predominantly the splice variant 1 (SV1) have been documented in breast cancer $(2,4-6)$. As evidence of an autocrine/paracrine regulatory mechanism, it has been shown that the knocking down of the GHRH gene expression in breast cancer cell lines with SiRNA results in reduced cellular proliferation (7). Similar effects are produced in prostate cancer and non-small cell lung cancer cell lines $(3,7)$. As additional support for autocrine/paracrine regulation is the transfection of the MCF7 cells (originally devoid of GHRH-R) with the GHRH-R which results in increased cellular proliferation after the addition of exogenous 
GHRH. This increase in proliferation is even greater when the transfection involves the SV1 receptor (8). The transfection of MCF-7 cells with the $\mathrm{SV} 1$ receptor results in increased proliferation even without the addition of exogenous GHRH, suggesting a GHRH-independent activation of this truncated receptor (8). Furthermore, GHRH-R antagonists have been found to be effective in the reduction of invasive and metastatic potential of human cancer cell lines in vitro by modifying cellular adhesion, migration, and survival (9). The antagonistic analogs of GHRH have been reported to consistently reduce or abolish the growth of several breast cancer models $(6,10,11)$, and therefore such antagonists have been proposed as potential targeted therapeutic agents for breast carcinoma.

The presence of the pGHRH-R and/or the SV1 receptor in cancer cells has been demonstrated by different techniques including RT-PCR (2, 4, 11, 12), Western blotting $(6,12)$, in situ hybridization (13), immunohistochemistry $(5,8,13,14)$ and radioreceptor assays (15). GHRH-Rs have been demonstrated in estrogen receptor dependent as well as independent breast carcinoma cell lines (11), in both ductal and lobular carcinomas $(5,13)$, in ductal carcinomas of various histological grades (5), but no systematic evaluation of breast cancer types has been performed to date.

There are different approaches for the classification of breast cancer from conventional histopathological/morphological appearance to molecular subtyping. The radiomorphological features of breast tumors also reflect their biological behavior and should be considered during disease management (16). The presence of casting-type microcalcification on the mammogram is a warning sign of aggressive tumor behavior, irrespective of the stage of the tumor $(17,18)$.

In this study, we analyzed a series of breast carcinomas for the expression of GHRH-R and correlated the presence of these receptors to histological features and morphological or biological subtypes of breast cancers.

\section{MATERIALS AND METHODS}

In this retrospective study, tissue blocks of 71 breast cancer patients from the archives of the Department of Pathology, University of Szeged were used. These were obtained either from total mastectomy or from partial mastectomy specimens. Only carcinomas $\leq 2 \mathrm{~cm}$ (pT1 tumors) $(19,20)$, were included in the study to limit the effect of tumor heterogeneity. Groups of different histological, molecular and clinicopathological types of breast cancer were selected. Histological types included invasive tubular, ductal (no special type, NST) and lobular (ILC) carcinomas as defined by the World Health Organization
(WHO) classification of breast tumors (21). Grading was performed on the basis of the Nottingham scheme (22). Molecular types were determined by means of the surrogate immunohistochemistry (IHC)-based approach using estrogen receptor (ER), progesterone receptor (PR), human epidermal growth factor receptor 2 (HER2) and $\mathrm{Ki}-67$ to classify breast carcinomas into luminal A, luminal B, HER2-enriched and triple-negative (including the basal-like) subtypes $(23,24)$. The antisera technologies of companies shown in Table 1 were used. On this basis, ER-positive tumors were classified as luminal A if they were HER2-negative and had a Ki-67 labeling index $<14 \%$; they were labeled as luminal $\mathrm{B}$ if they were either HER2-positive or had a Ki-67 labeling index $>13 \%$ or both. ER-negative tumors were classified either as HER2positive or as triple-negative (HER2-negative and PR-negative). Cases with casting-type microcalcification on the mammogram were also included in the study because these tumors have been reported to have an unfavorable outcome by some authors (16-18), and they are considered as a special entity by the multidisciplinary breast team at the University of Szeged. During the selection of the cases, we added to the study material 10 cases of carcinomas (of any size) with apocrine differentiation (apocrine carcinomas) recently diagnosed at the Department of Pathology, University of Szeged or at the Department of Pathology, Bács-Kiskun County Teaching Hospital.

Tissues were fixed in buffered formalin and embedded in paraffin. Four- to five-micrometer-thick whole tissue sections were used for the immunohistochemistry. The antibodies used are listed in Table 1. The stains for ER, PR, HER2 and in most cases Ki-67 were performed routinely and the results were available from the original reports. The interpretation of the ER, PR and HER2 stainings was according to the American Society of Clinical Oncology/College of American Pathologists guidelines (25, 26). Details of the anti-GHRH-R immunohistochemistry were as follows.

Deparaffinization (in xylene for $3 \times 3$ min, in $96 \%$ ethanol for $2 \times 3 \mathrm{~min}$ and in $70 \%$ ethanol for $3 \mathrm{~min}$ ) followed by rehydration $(2 \times 2$ min distilled water $)$ at room temperature was followed by antigen retrieval with the Dako PT Link system (Dako, Glostrup, Denmark) (10 mM Sodium Citrate buffer, $\mathrm{pH} 6$ for $15 \mathrm{~min}$ at $94{ }^{\circ} \mathrm{C}$ ). After being rinsed with Tris buffer saline - EnVision FLEX Wash (TBS) (Dako), the sections were placed in Dako Autostainer Link 48 (Dako) for endogenous

Table 1. List and details of antibodies used

\begin{tabular}{|c|c|c|c|}
\hline Antibody & Clonality & Company & Dilution \\
\hline GHRH-R & $\begin{array}{l}\text { Rabbit } \\
\text { polyclonal } \\
\text { (ab76263) }\end{array}$ & $\begin{array}{l}\text { Abcam } \\
\text { (Cambridge, } \\
\text { UK) }\end{array}$ & $1: 250$ \\
\hline ER & SP1 & $\begin{array}{l}\text { Lab Vision } \\
\text { (Thermo } \\
\text { Scientific, } \\
\text { Waltham, } \\
\text { MA, USA) }\end{array}$ & $1: 200$ \\
\hline PR & polyclonal & $\begin{array}{l}\text { Lab Vision } \\
\text { (Thermo } \\
\text { Scientific) }\end{array}$ & $1: 100$ \\
\hline HER2 & SP3 & $\begin{array}{l}\text { Histopathology } \\
\text { (Pécs, Hungary) }\end{array}$ & $1: 100$ \\
\hline Ki-67 & MIB-1 & DAKO & $1: 100$ \\
\hline
\end{tabular}


peroxidase blockage and staining. In the Autostainer, the sections were washed with TBS, blocked by FLEX Peroxidase-Blocking Reagent (Dako) (for $5 \mathrm{~min}$ ), incubated with the rabbit anti-GHRH-R polyclonal antibody at $56^{\circ} \mathrm{C}$ (diluted at 1:250) for $50 \mathrm{~min}$, rinsed (in TBS for $10 \mathrm{~min}$ ), and then incubated with the Dako EnVision FLEX (Rabbit) detection system (Dako) (in secondary antibody for $30 \mathrm{~min}$, TBS, in $\mathrm{DAB}+$ for $2 \times 7 \mathrm{~min}$, TBS). The sections were then counterstained with Mayer's hematoxylin, dehydrated (in $96 \%$ ethanol for $3 \times 3 \mathrm{~min}$, in acetone for $2 \times 3 \mathrm{~min}$ ), cleared in xylene (for $2 \times 2 \mathrm{~min}$ ), and mounted. Negative controls were carried out by omitting the primary antibody. Every slide included a pituitary gland tissue-chip to serve as positive control.

Specimens were evaluated only in the case of adequate staining in the controls. Positive staining of breast cancer tissue was classified according to the localization of immune reaction and percentage of positive tumor cells. On the basis of a previous report, both nuclear and cytoplasmic stainings were accepted as positive (13). The invasive component of the tumors was evaluated, and specimens below the cutoff level of $10 \%$ staining were considered negative.

Statistical analysis was performed with the chi-square test using the SPSS 20.0 (IBM, Armonk, NY, USA) statistical software, and the significance level chosen was $\mathrm{p}<0.05$.

Since all patient and disease information was gathered anonymously and retrospectively with no influence on patient outcome or treatment, no ethical permission was deemed necessary according to local regulations.

\section{RESULTS}

Seventy-one early breast cancer patients (one bilateral case) with 72 tumors were included in the present study. The clinicopathological features are summarized in Table 2.

Table 2. Basic characteristics of the patients and tumors

\begin{tabular}{lc}
\hline Age: median (range) & 61 years $(32-88)$ \\
\hline Tumor size: mean (range) & $13.6 \mathrm{~mm}(5-19)$ \\
Node-positive cases/node-negative & $25 / 47$ \\
$\quad$ cases & \\
Histological types & $4+42$ \\
$\quad$ Tubular + no special type & \\
(NST); ductal & 23 \\
ILC & $3(2,1)$ \\
Others (medullary, sarcomatoid) & \\
Histological grade & $11(15.3 \%)$ \\
Grade 1 & $29(40.2 \%)$ \\
Grade 2 & $32(44.4 \%)$ \\
Grade 3 & $28(38.9 \%)$ \\
IHC-based molecular types & $9(12.5 \%)[3]$ \\
Luminal A & $12(16.7 \%)$ \\
Luminal B [HER2-positive & $19(26.4 \%)$ \\
subset] & \\
HER2-enriched & $4(5.6 \%)$ \\
Triple negative (inclusive of & \\
basal-like) & \\
Not classified &
\end{tabular}

Cytoplasmic, nuclear, or combined GHRH positivity was detected in $42 / 72(0.58)$ of the cases. Considering the most common histological types (tubular carcinomas were lumped together with NST ductal carcinomas), ILCs displayed GHRH-R positivity more often than ductal carcinomas: 20/23 (0.87; $95 \%$ confidence interval $(\mathrm{CI}): 0.68-0.95)$ vs 22/46 (0.48; 95\% CI: 0.34-0.62) ( $\mathrm{p}=0.002$, Pearson chi-square). Five of the ILCs were pleomorphic on the basis of cellular morphology and combined histological grade 3; all were positive for GHRH-R.

Positivity of staining according to the histological grade of the tumors is shown in Fig. 1. Interestingly, the highest proportion of tumors demonstrating GHRH-R positivity $(25 / 29 ; 0.86 ; 95 \% \mathrm{CI}$ : 0.69-0.95) was seen in grade 2 carcinomas, whereas this proportion was lower for grade $1(2 / 11 ; 0.18$; 95\% CI: $0.05-0.48)$ and grade 3 (15/32; $0.47 ; 95 \%$ CI: $0.31-0.64)$ tumors. To assess the relation of GHRH-R expression and proliferation, the mitotic score was used, as an ordinal variable standardizing mitotic counts to the area of the high power field of the microscopes, but no association was found

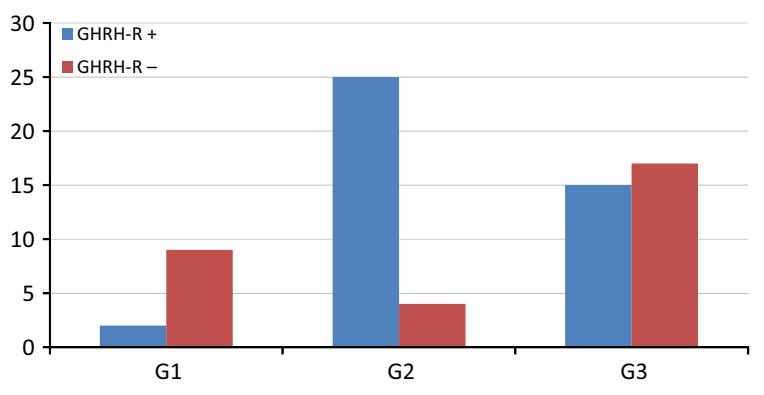

Fig. 1. Distribution of GHRH-R-positive and GHRH-Rnegative cases according to the grade of differentiation of breast carcinomas.

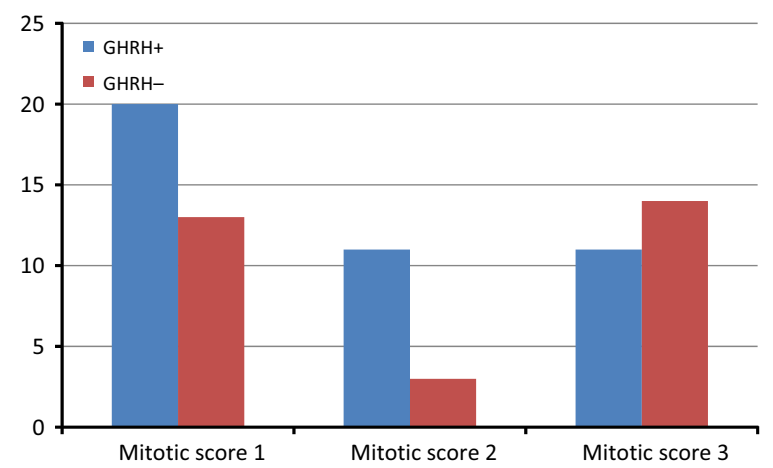

Fig. 2. Distribution of GHRH-R-positive and GHRH-Rnegative cases according to the mitotic score component of the histological grade of breast carcinomas. 
(Fig. 2). Similarly, there was no significant difference in the Ki-67 labeling indices (LI) of GHRH-R positive and negative tumors, where the average LIs were 18.3 and 28.3 , respectively $(p=0.18)$, although Ki-67 LIs were available in only 51 cases.

There was no association between nodal status and GRHR-R staining: $13 / 42(0.31 ; 95 \%$ CI: 0.19 $0.46)$ of the GHRH-R-positive tumors were nodepositive, and this proportion was $12 / 30(0.4 ; 95 \%$ CI: $0.25-0.58)$ for the GHRH-R-negative cases ( $\mathrm{p}=0.43$, Pearson chi-square).

According to the IHC-based surrogate molecular classification, GHRH-R positivity was observed in 17/28 (0.61; 95\% CI: 0.42-0.76) luminal A (ERpositive, HER2-negative, Ki-67 < 14\%), 8/9 (0.89; 95\% CI: 0.57-0.98) luminal B (ER-positive and either HER2-positive or Ki-67 > 13\% or both), 7/ 12 (0.58; 95\% CI: 0.32-0.081) HER2-enriched (ERnegative and HER2-positive) and 6/19 (0.32\%; 95\% CI: 0.15-0.54) triple-negative carcinomas (ERnegative, PR-negative and HER2-negative) (Fig. 3). The luminal B tumor with negative GHRH-R status was a HER2-negative carcinoma with high proliferation rate (Ki-67 labeling: 25\%).

As a special clinical entity, 12 tumors with casting-type calcifications on the mammogram were also included in the study. Nine of these cases showed GHRH-R positivity $(0.75$; 95\% CI: $0.47-$ 0.91). The carcinomas with casting-type calcifications represented NST ductal carcinomas, with heterogeneity in terms of hormone receptor (seven were ER-positive and five of these were also PRpositive) and HER2 status (four were positive). As concerns the molecular types according to the IHCbased classification, all four types were represented. The GHRH-R-negative cases belonged to the luminal A $(n=2)$ or the HER2-enriched $(n=1)$ types.

During the analysis of the cases, we observed a consistent and strong staining for GHRH-R in foci of apocrine metaplasia (Fig. 4). To investigate this unanticipated phenomenon, we included 10 cases of recently diagnosed apocrine carcinomas - as

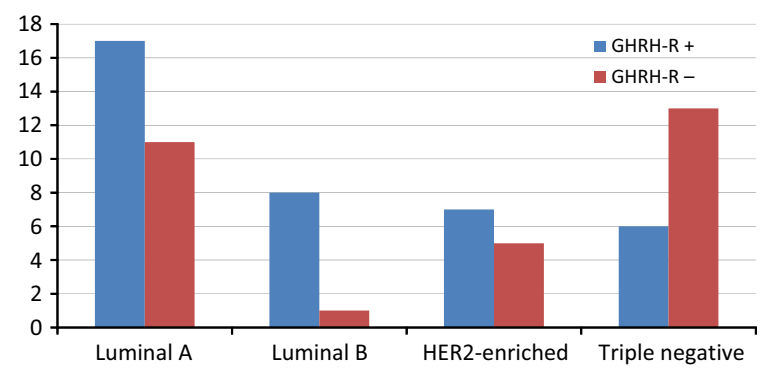

Fig. 3. Distribution of GHRH-R-positive and GHRH-Rnegative cases according to the molecular subtypes of breast carcinomas determined by IHC. defined by the recent WHO classification of breast tumors (21), all of which showed strong and diffuse GHRH-R positivity (Fig. 4). All the apocrine carcinomas studied were negative for ER and PR; seven of them were HER2-negative as well, whereas two tumors were positive for HER2 and one case of apocrine ductal carcinoma in situ apocrine was not tested for this marker. All 10 cases were positive for the apocrine marker GCDPF-15 and four cases tested for androgen receptor were all positive. No attempts were made in this study to distinguish between pGHRH-R and SV1 since this would require the use of more specific antisera for IHC which are still under development.

\section{DISCUSSION}

The endocrine effect of GHRH on cancer has been thought to be rendered by the stimulation of the $\mathrm{GHRH} / \mathrm{GH} / \mathrm{IGF}-1$ axis. Recently, an additional autocrine/paracrine role in the regulation of proliferation and differentiation of cancer cells has been proposed. The latter mechanism is supported by the presence of GHRH in various malignancies as demonstrated by means of mRNA expression by the detection of immuno-reactive and biologically active GHRH and by the identification of its receptors in different human cancers $(1-4,12)$. GHRH antagonists have been tested as potential targeted therapeutic agents in several malignancies, including breast cancers $(6,10,11)$.

The incidence of GHRH-R expression in different breast cancer subtypes (histological, molecular and clinical) has not yet been investigated extensively. Since the presence of the GHRH-R could be a selection criterion for potential treatment targeted to GHRH-R, it was thought that a pilot study identifying potential subsets of tumors preferentially expressing the receptor could be of relevance. To elucidate the possible presence of GHRH-R in the individual subtypes, we selected tissue blocks of different histological and molecular types from our archives, and examined the expression of GHRH-R with IHC.

As concerns the different histologic types of breast cancer, there are many based on special features, but the two major types are ductal carcinomas NST and lobular carcinomas. Other subtypes are less frequent, and are sometimes viewed as special types of ductal (non-lobular) carcinomas. In our study, ILCs were significantly more frequently positive for GHRH-R. A previous report has identified lobular carcinomas to have a higher rate of GHRH expression than ductal carcinomas, which could support an autocrine/paracrine regulatory 

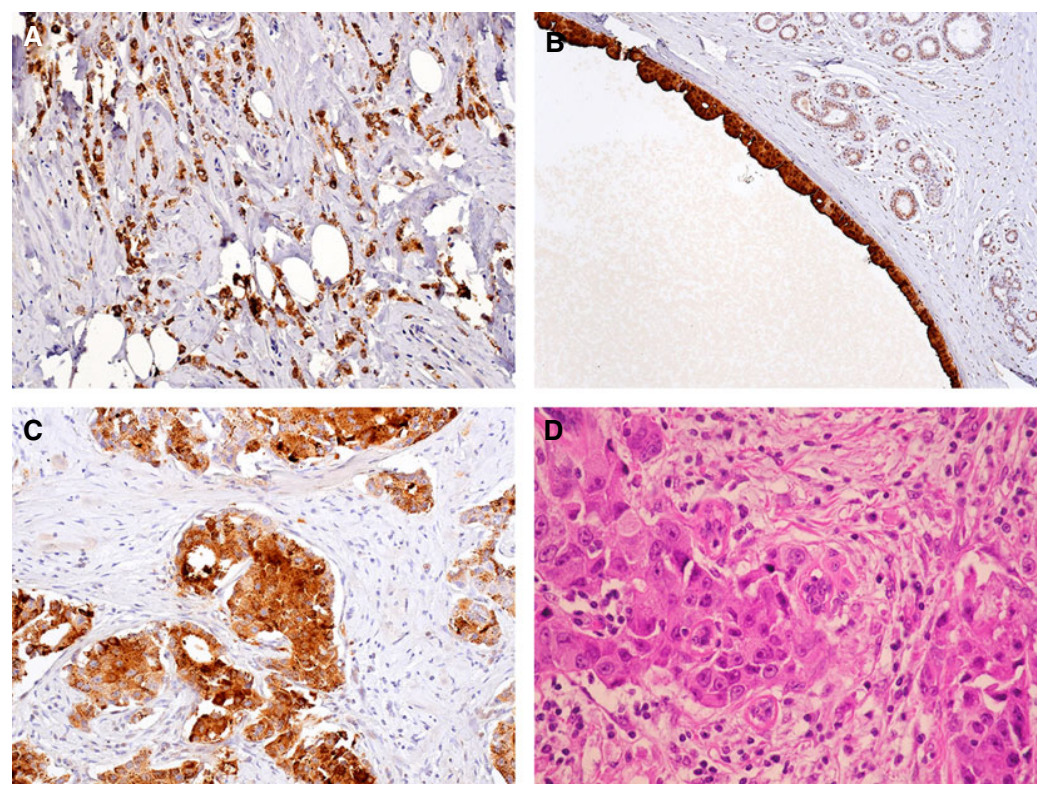

Fig. 4. Examples of GHRH-R positivity in different histological entities. (A) lobular carcinoma (GHRH-R x20); (B) apocrine cyst (GHRH-R x10); (C-D) no special type (ductal) carcinoma with apocrine differentiation, i.e., apocrine carcinoma (C: GHRH-R x20, D: HE x40).

effect. The same study failed to document a similar predilection for the distribution of SV1 using a polyclonal antibody which is no longer available (5). In that study, only 1 of 6 lobular carcinomas was positive for SV1. The contrary finding that most ILCs were positive for GHRH-R in our analysis, could probably be explained by the use of a different antibody that detects both the pGHRH$\mathrm{R}$ and the SV1 receptor. Since the antibody (ab76263) used in our study was raised against a synthetic peptide derived from the internal region of the human pGHRH-R (27), and the biologically active SV1 differs from the full length pituitary receptor only in its $\mathrm{N}$-terminal part (2), the antibody recognizes the full length GRHR-R along with the SV1, but not the much shorter (145-amino acid-long) SV2.

As concerns the grades of differentiation of breast cancer, no significant association was found with the GHRH-R status, although grade 2 tumors seemed to show GHRH-R positivity more frequently than grade 1 or 3 tumors. Reports on the distribution of GHRH-R by grade are scarce. Chatzistamou et al. suggested no predilection for any level of differentiation: $2 / 2$ of grade $1,5 / 16$ of grade 2 , and $6 / 22$ of grade 3 ductal carcinomas were identified as positive (5). The reasons for finding more positive cases among grade 2 tumors are not clear, especially in the light of molecular studies. Sotiriou and colleagues have demonstrated that gene expression profile-based genomic grades matched well histological grades 1 and 3 , but breast tumors classified as histological grade 2 fell either into the category of low or high genomic grade (28). Therefore, histologic grade 2 tumors cannot be classified morphologically into high or low grade, resulting in an intermediate prognosis due to this dual composition. Our results, as well as the previous report cited, suggest that GHRH-R positivity can occur in any grade of breast cancer, and there seems to be no real predilection for any grade. In keeping with the results relating to the differentiation of the carcinomas, no association was found with proliferation whether assessed by mitotic scores or the $\mathrm{Ki}-67$ proliferation marker. There was also no association of GHRH-R expression and the nodal status of breast carcinomas.

The study also incorporated 12 cases with casting-type microcalcification on the mammogram. The clinical outcome of this entity is still subject to some debate with some authors and results reinforcing the finding of a poor outcome $(16-18,29$ $31)$ and others refuting it $(32,33)$. Our experience supports the poor outcome of these tumors, and is why such cases were separately studied for their GHRH-R expression (18). Although the authors originally describing this entity as one associated with poor prognosis did not specifically report the distribution of this type of carcinoma presentation according to molecular subtypes, they suggested that many of these tumors were HER2-positive (17), with HER2 positivity being three times more 
frequent in this subgroup than in breast carcinomas without casting-type calcifications (Tot T., personal communication 2013 July). The present series of small tumors included carcinomas with casting-type microcalcifications with heterogeneous grade and molecular type distribution, and only one-third were HER2-positive. All cases with casting-type calcifications were associated with high grade ductal carcinoma in situ showing comedo necrosis and microcalcification. GHRH-R positivity was observed in $75 \%$ of the cases of this clinical/mammographical entity which is almost double the $40 \%$ positivity rate of ductal NST carcinomas without casting-type microcalcification; this difference failed to be statistically significant. The relevance of these findings is not yet known, but further study is warranted to clarify this issue.

Growth hormone-releasing hormone receptors positivity was seen in all molecular types of breast cancer, including ER-positive and ER-negative cases, in keeping with results found with cell lines (11). All but one of the luminal B tumors demonstrated strong and diffuse immune reaction with anti-GHRH-R, but as even luminal B tumors are heterogeneous, the significance of this finding in a relatively low number of cases is uncertain.

Even though triple-negative breast cancers showed GHRH-R positivity in a relatively low percentage $(32 \%)$, the unfavorable prognosis and the limited therapeutic modalities for these carcinomas emphasize the importance of this group. Targeted anti-GHRH therapy proved to be efficient in the treatment of nude mice transplanted with human triple-negative breast cancer xenografts (34). Further investigations are necessary to clarify whether triple-negative cancers expressing the GHRH-R could be treated with GHRH antagonists.

As a caveat, it must be remembered that the present pilot study did not include consecutively diagnosed breast carcinomas, and therefore the proportion of staining tumors may only be an estimate, requiring confirmation on a larger group of tumors. A strength, however, is that we chose to limit tumor heterogeneity by studying relatively small (pT1) cancers.

During the analysis of the cases, we noticed a pronounced, uniform GHRH-R expression in cysts showing apocrine metaplasia. This finding inspired us to investigate the expression of GHRH-R in cancers showing apocrine differentiation and to include 10 cases of apocrine carcinoma (both in situ and invasive tumors). All of these consistently demonstrated a strong and diffuse positivity. Apocrine carcinomas are defined as carcinomas in which the cells demonstrate the cytological features of apocrine cells (21), they are often ER-negative and PR-negative, but androgen receptor (AR)-positive tumors (35), and express apocrine markers like gross cystic disease fluid protein-15 (GCDFP-15). As concerns the molecular types approached by IHC, a part of these neoplasms belongs to the HER2-enriched group, but the majority of them are triple negative. A molecular apocrine type of breast cancers with increased androgen signaling has also been described, and is characterized by ER negativity and AR positivity (21, 36-38). The overlap between breast cancers classified as apocrine on the basis of gene expression profile vs morphologic features is not complete. It has been estimated that the apocrine gene expression profile may be present in $8-14 \%$ of breast cancers, whereas apocrine carcinomas classified on the basis of morphologic appearance are relatively rare, comprising about $4 \%$ of breast carcinomas (21); part of them may be a subset of triple-negative breast cancers. Their androgen-dependent signaling pathway could also suggest a specific treatment. Whether their homogeneous positivity for GHRH-R can be translated to a targeted therapy with GHRH antagonists which are under development for clinical use requires further studies.

\section{CONCLUSION}

Our study demonstrates that the distribution of GHRH-R among breast carcinomas is not restricted to histological type, differentiation grades or molecular subtypes. ILCs were found to express this marker more frequently than ductal NST carcinomas. The finding of a relatively high proportion of positivity among ductal NST carcinomas with casting-type microcalcification is of uncertain significance. The most important finding of this study, we feel is that apocrine epithelium (both benign and malignant) stains diffusely and strongly for GHRH-R. Whether this phenomenon can be used for targeting apocrine carcinomas with GHRH antagonists is to be clarified in future studies.

The authors acknowledge the support of the TÁMOP4.2.2.A-11/1/KONV-2012-0 project. We are grateful to Dr. Norman L. Block for useful suggestions and editorial revisions.

\section{REFERENCES}

1. Kahán Z, Arencibia JM, Csernus VJ, Groot K, Kineman RD, Robinson WR, et al. Expression of growth hormone-releasing hormone (GHRH) messenger ribonucleic acid and the presence of biologically active 
GHRH in human breast, endometrial, and ovarian cancers. J Clin Endocrinol Metab 1999;84:582-9.

2. Rekasi Z, Czompoly T, Schally AV, Halmos G. Isolation and sequencing of cDNAs of splice variants of growth hormone-releasing hormone receptors from human cancers. Proc Natl Acad Sci U S A 2000;97:10561-6.

3. Schally AV, Varga JL, Engel JB. Antagonists of growth-hormone-releasing hormone: an emerging new therapy for cancer. Nat Clin Pract Endocrinol Metab 2008;4:33-43.

4. Garcia-Fernandez MO, Schally AV, Varga JL, Groot K, Busto R. The expression of growth hormone-releasing hormone (GHRH) and its receptor splice variants in human breast cancer lines; the evaluation of signaling mechanisms in the stimulation of cell proliferation. Breast Cancer Res Treat 2003;77:15-26.

5. Chatzistamou I, Schally AV, Kiaris H, Politi E, Varga $\mathrm{J}$, Kanellis $\mathrm{G}$, et al. Immunohistochemical detection of GHRH and its receptor splice variant 1 in primary human breast cancers. Eur J Endocr 2004;151:391-6.

6. Köster F, Engel JB, Schally AV, Hönig A, Schröer A, Seitz S, et al. Triple-negative breast cancers express receptors for growth hormone-releasing hormone $(\mathrm{GHRH})$ and respond to GHRH antagonists with growth inhibition. Breast Cancer Res Treat 2009;116:273-9.

7. Barabutis N, Schally AV. Knocking down gene expression for growth hormone-releasing hormone inhibits proliferation of human cancer cell lines. $\mathrm{Br} \mathrm{J}$ Cancer 2008;98:1790-6.

8. Barabutis N, Tsellou E, Schally AV, Kouloheri S, Kalofoutis A, Kiaris H. Stimulation of proliferation of MCF-7 breast cancer cells by a transfected splice variant of growth hormone-releasing hormone receptor. Proc Natl Acad Sci U S A 2007;104:5575-9.

9. Bellyei S, Schally AV, Zarandi M, Varga JL, Vidaurre I, Pozsgai E. GHRH antagonists reduce the invasive and metastatic potential of human cancer cell lines in vitro. Cancer Lett 2010;293:31-40.

10. Kahán Z, Varga JL, Schally AV, Rekasi Z, Armatis $\mathrm{P}$, Chatzistamou L, et al. Antagonists of growth hormone-releasing hormone arrest the growth of MDAMB-468 estrogen-independent human breast cancers in nude mice. Breast Cancer Res Treat 2000;60:71-79.

11. Seitz S, Hohla F, Schally AV, Moder A, Engel JB, Horn $\mathrm{F}$, et al. Inhibition of estrogen receptor positive and negative breast cancer cell lines with a growth hormone-releasing hormone antagonist. Oncol Rep 2008;20:1289-94.

12. Havt A, Schally AV, Halmos G, Varga JL, Toller GL, Horvath JE, et al. The expression of the pituitary GHRH receptor and its splice variants in normal and neoplastic human tissues. Proc Natl Acad Sci U S A 2005;102:17424-9.

13. Gallego R, Pintos E, García-Caballero T, Raghay K, Boulanger L, Beiras A, et al. Cellular distribution of growth hormone-releasing hormone receptor in human reproductive system and breast and prostate cancers. Histol Histopathol 2005;20:697-706.

14. Schulz S, Röcken C, Schulz S. Immunocytochemical localisation of plasma membrane GHRH receptors in human tumours using a novel anti-peptide antibody. Eur J Cancer 2006;42:2390-6.
15. Halmos G, Schally AV, Czompoly T, Krupa M, Varga JL, Rekasi Z. Expression of growth hormonereleasing hormone and its receptor splice variants in human prostate cancer. J Clin Endocrinol Metab 2002;87:4707-14.

16. Tabár L, Chen HH, Yen MF, Tot T, Tung TH, Chen LS, et al. Mammographic tumor features can predict long-term outcomes reliably in women with 1-14-mm invasive breast carcinoma. Cancer 2004;101:1745-59.

17. Tabár L, Tot T, Dean PB. Breast Cancer - Early Detection with Mammography. Casting Type Calcifications: Sign of a Subtype with Deceptive Features. Stuttgart: Thieme, 2007.

18. Pálka I, Ormándi K, Gaál S, Boda K, Kahán Z. Casting-type calcifications on the mammogram suggest a higher probability of early relapse and death among high-risk breast cancer patients. Acta Oncol 2007;46:1178-83.

19. Sobin L, Gospodarowicz M, Wittekind $\mathrm{CH}$, editors. UICC TNM Classification of Malignant Tumours, 7th edn. New York: John Wiley and Sons Inc., 2009.

20. Edge SB, Byrd DR, Compton CC, Fritz AG, Greene FL, Trotti A, editors. AJCC Cancer Staging Handbook: From the AJCC Cancer Staging Manual. New York: Springer, 2009.

21. Lakhani SR, Ellis IO, Schnitt SJ, Tan PH, van de Vijver MJ, editors. WHO Classification of Tumours of the Breast. International Agency for Research on Cancer: Lyon, 2012.

22. Elston CW, Ellis IO. Pathological prognostic factors in breast cancer. I. The value of histological grade in breast cancer: experience from a large study with long-term follow-up. Histopathology 1991;19:403-10.

23. Cheang MCU, Chia SK, Voduc D, Gao D, Leung S, Snider J, et al. Ki67 index, HER2 status, and prognosis of patients with luminal B breast cancer. J Natl Cancer Inst 2009;101:736-50.

24. Goldhirsch A, Wood WC, Coates AS, Gelber RD, Thürlimann B, Senn HJ, et al. Strategies for subtypes - dealing with the diversity of breast cancer: highlights of the St. Gallen International Expert Consensus on the Primary Therapy of Early Breast Cancer 2011. Ann Oncol 2011;22:1736-47.

25. Wolff AC, Hammond ME, Schwartz JN, Hagerty KL, Allred DC, Cote RJ, et al. American Society of Clinical Oncology/College of American Pathologists guideline recommendations for human epidermal growth factor receptor 2 testing in breast cancer. J Clin Oncol 2007;25:118-45.

26. Hammond ME, Hayes DF, Dowsett M, Allred DC, Hagerty KL, Badve S, et al. American Society of Clinical Oncology/College of American Pathologists guideline recommendations for immunohistochemical testing of estrogen and progesterone receptors in breast cancer. Arch Pathol Lab Med 2010;134:e48-72.

27. Product datasheet - Anti-GHRHR antibody ab76263. Available at: http://www.abcam.com/ (accessed 9 June 2013).

28. Sotiriou C, Wirapati P, Loi S, Harris A, Fox S, Smeds $\mathbf{J}$, et al. Gene expression profiling in breast cancer: understanding the molecular basis of histologic grade to improve prognosis. J Natl Cancer Inst 2006;98:262-72.

29. Tabár L, Chen HH, Duffy SW, Yen MF, Chiang CF, Dean $\mathrm{PB}$, et al. A novel method for prediction of 
long-term outcome of women with T1a, T1b, and 10$14 \mathrm{~mm}$ invasive breast cancers: a prospective study. Lancet 2000;355(9202):429-33.

30. Zunzunegui RG, Chung MA, Oruwari J, Golding D, Marchant DJ, Cady B. Casting-type calcifications with invasion and high-grade ductal carcinoma in situ: a more aggressive disease? Arch Surg 2003;138: 537-40.

31. Bennett RL, Evans AJ, Kutt E, Record C, Bobrow LG, Ellis IO, et al. Pathological and mammographic prognostic factors for screen detected cancers in a multi-centre randomised, controlled trial of mammographic screening in women from age 40 to 48 years. Breast 2011;20:525-8.

32. James JJ, Evans AJ, Pinder SE, Macmillan RD, Wilson AR, Ellis IO. Is the presence of mammographic comedo calcification really a prognostic factor for small screen-detected invasive breast cancers? Clin Radiol 2003;58:54-62.

33. Månsson E, Bergkvist L, Christenson G, Persson C, Wärnberg F. Mammographic casting-type calcifications is not a prognostic factor in unifocal small invasive breast cancer: a population-based retrospective cohort study. J Surg Oncol 2009;100:670-4.

34. Seitz S, Rick FG, Schally AV, Treszl A, Hohla F, Szalontay L, et al. Combination of GHRH antagonists and docetaxel shows experimental effectiveness for the treatment of triple-negative breast cancers. Oncol Rep 2013;30:413-8.

35. Tsutsumi Y. Apocrine carcinoma as triple-negative breast cancer: novel definition of apocrine-type carcinoma as estrogen/progesterone receptor-negative and androgen receptor-positive invasive ductal carcinoma. Jpn J Clin Oncol 2012;42:375-86.

36. Farmer P, Bonnefoi H, Becette V, Tubiana-Hulin M, Fumoleau P, Larsimont D, et al. Identification of molecular apocrine breast tumors by microarray analysis. Oncogene 2005;24:4660-71.

37. Wilkerson PM, Dedes KJ, Lopez-Garcia MA, ReisFilho JS. The molecular evolution of breast cancer precursors and risk indicators. In: Kahán Z, Tot T, editors. Breast Cancer, a Heterogeneous Disease Entity - The Very Early Stages. Dordrecht-Heidelberg-London-New York: Springer Science + Business Media, 2011: 89-118.

38. Dedes KJ, Wilkerson PM, Reis-Filho JS. Immunohistochemistry and molecular biology of breast cancers: Old and new prognostic factors. In: Kahán Z, Tot T, editors. Breast Cancer, a Heterogeneous Disease Entity - The Very Early Stages. Dordrecht-Heidelberg-London-New York: Springer Science+Business Media, 2011: 119-48. 